\title{
SPOUSES' EXPERIENCES OF MEALTIMES WITH A PARTNER SUFFERING FROM DEMENTIA
}

\author{
L. Johansson, A. Björklund, B. Sidenvall, L. Christensson
}

\begin{abstract}
Background: As difficulties in performing daily activities occur among persons with dementia, their spouses are also affected. This is also true for mealtimes, yet there is a lack of knowledge and research into how couples manage this situation at home. Objective: The aim of the study was to explore and describe spouses' experiences of mealtimes in couples in which one partner has dementia. Design, Setting and Participants: Ten spouses were interviewed in their home in respect to their experiences regarding mealtimes when living with a partner diagnosed with dementia. To identify themes across the data set, thematic analysis was conducted. Results: One major theme, Recognizing and managing the range of mealtime change, was identified and showed that depending on where the families were in the dementia process their experienced varied. As progression occurred in the partners disease, routines, responsibilities and relationships were affected within the couple. Strategies the participants used to manage mealtimes at home regarding these problems were highlighted such as getting support from social services, but also strategies they had learnt by themselves. Conclusion: These results generate an insight into what couples face, and their needs for support. Spouses experiences varied which indicates that it is important that support is based on individual needs. Hence, nursing staff should continuously pay attention to couples mealtime situation. Further it increases staff's knowledge regarding possible solutions on how to involve persons with dementia in mealtime activities and maintain their nutritional intake.
\end{abstract}

Key words: Dementia, mealtimes, qualitative research, spouses.

\section{Introduction}

The process of dementia disease gradually affects a person's ability to manage their daily life, as one's functional capacity decreases and difficulties in performing activities arise $(1,2)$. When dealing with mealtime situations, problems with preparing and eating food have been found $(3,4)$, with decreased cognitive function found to be associated with malnutrition (5). The partner of a person with dementia is also affected by the disease, and it has been described that the partner may experience a transition in the relationship whereby they become more of a caregiver, than a partner (6). For the purpose of this study, the term mealtime refers to the preparation and consumption of food or a meal. The term meal refers to the food consumed.

Studying mealtime experiences of spouses living with a partner with dementia has revealed that eating together is a social activity and something enjovable,

Department of Nursing and Institute of Gerontology, School of Health Sciences, Jönköping University, Jönköping, Sweden

Corresponding Author: Linda Johansson, Department of Nursing, Institute of Gerontology, School of Health Sciences, Jönköping University, P.O. Box 1026, S - 55111 Jönköping, Sweden. Tel:+4636101253. E-mail: linda.johansson@hhj.hj.se. Fax: +4636101250 as well as a highlight of the day for some (7). However, changes and difficulties might occur, and, nursing staff have emphasized that a spouse can be both someone supporting the person with dementia as well as someone in need of support him/herself (8). Spouses experiences of mealtime situations seem to differ in relation to previous roles in the family prior to the development of dementia. These changes also affect the spouses' daily life in regards to the planning and preparing of meals, with frustration, stress and conflict emanating from mealtime changes having been described (7). Further, female caregivers have described a transition from working as a team to having the main responsibility and doing things alone; i.e., having to extend their current role as food provider. Male caregivers, however, state that they have experienced, as a result of their partner's disease, that they had been forced to take over the responsibility specifically for the preparation of meals, and that it had become a challenge to perform such activities (9). To adjust to living with this new situation, men described shifting from a passive role to an active one as food provider, while their female partners with dementia instead become increasingly passive as a result of a decreased capacity to manage this activity. At the beginning of the disease process, the wife with dementia was the expert and the husband needed her knowledge 
to carry out meal preparation, but this shifted over time (10). Male caregivers have also described having learned that preparing meals is much more than just cooking when taking over this responsibility, and that it was harder than their female partner had previously made it seem (11). Despite struggling with new responsibilities, pride in preparing meals while caring for their partner has also been expressed $(12,13)$.

The national policy, regarding elderly care in Sweden, is that older persons should live in their own homes as long as possible (14), and this also seems to be important to older persons themselves $(15,16)$. However, those with dementia tend to move to special housing more often than others (17), and the caregiver burden seems to be one reason for the need for this move (18). There is a gap of knowledge in respects to the mealtime situations in the home, and further research is needed (3) to possibly show how couples adjust to and manage changes, which could help nursing staff increase their understanding regarding what families struggle with and how to support them in prolonging independent living. In addition, Genoe et al., (19) point out that the meals for persons with dementia need to be investigated in different contexts and cultures, as the significance of mealtimes might differ. This present study highlights the voices of spouses of persons with dementia in Sweden concerning mealtimes, which includes how persons choose, prepare, serve, and eat their food (20). The aim of the study was to explore and describe spouses' experiences of mealtimes in couples in which one partner has dementia.

\section{Method}

\section{Design}

A qualitative explorative and descriptive interview study was performed. A thematic analysis was adopted since it aims to find repeated patterns and meanings across a data set (21).

\section{Participants}

During a home visit, all spouses living together with a person with dementia were asked to participate and received written and oral information about the study $(n=11)$. The persons with dementia $(n=35)$ had already participated in a project called Food, Exercise and Memory Loss which examined whether or not individual exercise and food interventions could improve the patients' health-related quality of life. The project have been further described (8). This study is comprised of the ten (six women and four men) spouses of individuals with dementia that were willing to tell about their mealtimes. Participants' characteristics are presented in Table 1 . The partners' with dementia cognitive ability, measured using the Mini Mental State Examination

Table 1

Participants' characteristics

\begin{tabular}{|c|c|c|c|c|}
\hline Participant & Age & Gender & Living status & Food activities \\
\hline $\mathrm{A}$ & 70 & Female & $\begin{array}{l}\text { Married and lives with husband } \\
\text { in house. }\end{array}$ & $\begin{array}{l}\text { Responsible for cooking even before partner was diagnosed with } \\
\text { dementia. Now cooks homemade food and buys groceries herself. }\end{array}$ \\
\hline B & 80 & Female & $\begin{array}{l}\text { Married and lives with husband } \\
\text { in apartment. }\end{array}$ & $\begin{array}{l}\text { Responsible for cooking even before partner was diagnosed with } \\
\text { dementia. Now cooks homemade food alone, and buys groceries } \\
\text { together with her partner. }\end{array}$ \\
\hline $\mathrm{C}$ & 83 & Female & $\begin{array}{l}\text { Married and lives with husband } \\
\text { in apartment. }\end{array}$ & $\begin{array}{l}\text { Responsible for cooking even before partner was diagnosed with } \\
\text { dementia. Now cooks homemade food and buys groceries herself. }\end{array}$ \\
\hline $\mathrm{D}$ & 79 & Female & $\begin{array}{l}\text { Married and lives with husband } \\
\text { in apartment. }\end{array}$ & $\begin{array}{l}\text { Responsible for cooking even before partner was diagnosed with } \\
\text { dementia. Now cooks homemade food alone, and buys groceries } \\
\text { together with her partner. }\end{array}$ \\
\hline $\mathrm{E}$ & 73 & Female & $\begin{array}{l}\text { Married and lives with husband } \\
\text { in house. }\end{array}$ & $\begin{array}{l}\text { Responsible for cooking even before partner was diagnosed with } \\
\text { dementia. Now cooks homemade food and buys groceries herself. }\end{array}$ \\
\hline $\mathrm{F}$ & 76 & Female & $\begin{array}{l}\text { Married and lives with husband } \\
\text { in house. }\end{array}$ & $\begin{array}{l}\text { Responsible for cooking even before partner was diagnosed with } \\
\text { dementia. Now cooks homemade food and buys groceries herself. }\end{array}$ \\
\hline G & 78 & Male & $\begin{array}{l}\text { Married and lives with wife in . } \\
\text { house }\end{array}$ & $\begin{array}{l}\text { Responsible for cooking even before partner was diagnosed with } \\
\text { dementia1. Now cooks homemade food alone, and buys groceries } \\
\text { together with his partner. }\end{array}$ \\
\hline $\mathrm{H}$ & 86 & Male & $\begin{array}{l}\text { Married and lives with wife in } \\
\text { townhouse. } \\
\text { partner. }\end{array}$ & $\begin{array}{l}\text { Partner used to be responsible for cooking before being diagnosed with } \\
\text { dementia }{ }^{1} \text {. Now cooks homemade food and buys groceries together with }\end{array}$ \\
\hline I & 86 & Male & $\begin{array}{l}\text { Married and lives with wife in } \\
\text { apartment. }\end{array}$ & $\begin{array}{l}\text { Partner was responsible for cooking before being diagnosed with } \\
\text { dementia. Now receives meals-on-wheels from the home-help service } \\
\text { and buys groceries himself. }\end{array}$ \\
\hline $\mathrm{J}$ & 63 & Male & Lives with partner in house. & $\begin{array}{l}\text { Responsible for cooking even before partner was diagnosed with } \\
\text { dementia. Now cooks homemade food alone, and buys groceries } \\
\text { together with his partner. }\end{array}$ \\
\hline
\end{tabular}

1. In these cases the participants had taken over the main responsibility later in life, e.g. after retirement. 
(MMSE), ranged between 16 and 30. It should be noted that it is not definitive how MMSE scores should be interpreted, but it has been suggested that 20 points or more indicates mild dementia, 10-19 moderate, and less than 10 severe (22).

\section{Data collection}

The data were collected during the years 2008-2009. The spouses were interviewed by the first author six to twelve months after their partner, who was participating in the project Food, Exercise and Memory Loss, had been diagnosed with dementia. A second meeting took place, two to four weeks after the initial interview, to clarify and confirm comments made by the participant in the interview. Participation in the study was voluntary, and participants could choose the place for the interview. All participants were interviewed in their home. Of the 10 participants, two chose to be interviewed when their partner was at the day care centre, and the remaining eight interviews carried out in a room where the partner was not present. Semi-structured interviews were conducted (23), with the aim to stimulate the spouses to speak freely about the subject. An interview guide was used in order to cover different aspects of mealtimes. The participants were first asked to describe the most recent meal in the household, and based on this description questions were asked about the cooking, eating, setting the table and changes regarding these activities, if any. The interviews lasted from 13 to 45 minutes, and were all recorded and transcribed verbatim. Field notes were made by the interviewer immediately after each interview, including both observations and personal thoughts.

\section{Data analysis}

An inductive analysis process was used. The analysis started with writing summaries based on data from each interview as well as field notes, to get an overall understanding of the content. These summaries were then discussed with each spouse during a second home visit. These discussions, were also recorded and transcribed, and aimed to check that everything had been understood correctly in the interview. Hence, this can be understood as a member check (24) and also offered the opportunity to ask follow-up questions if something was unclear to the researcher. In one case, the second home visit was not carried out because of illness in the family, but data from the interview were included in the data analysis. The analysis continued with a thematic analysis including six phases: becoming familiar with the data, creating initial codes, searching for themes, revising themes, defining and labeling themes and writing the results (21). Here, all of the transcribed data from the interview and the second home visit were read several times by the first author (L.J) to get an understanding of the content as a whole. Data including the spouses' experiences of meals were coded, and the codes were sorted into potential themes. Potential themes were discussed with the third author (B.S), tested and reworked when necessary, with a constant moving between the data as a whole and the codes, to search for patterns of meaning (Table 2). Finally, one theme emerged describing the content of the interviews.

\section{Ethical considerations}

When the partners of people with dementia were at home, they were informed that their spouses were being interviewed about their mealtimes which they seemed to accept without need for further explanation. Confidentiality was guaranteed, and approval for the project was granted by the local ethics committee (Dnr M15-08).

\section{Results}

One major theme, Recognizing and managing the range of mealtime changes was identified. It was found that depending on where the families were in the stage of dementia progression, their experiences varied. This major theme consisted of six subthemes. When problems were identified, solutions to address these problems was highlighted by the participants. Details of these problems and solutions will be presented.

\section{Continuing to have a familiar mealtime}

The results identified that sometimes mealtimes functioned quite well despite the partners dementia, especially compared with other things in daily life that affected the couple more, such as the partner's inability to take care of home economics and personal hygiene. Partners with dementia were still able to carry out meal preparation independently. This could include buying food, cooking and baking, setting the table, peeling vegetables or washing the dishes. Eating was often referred to by the participants as something that worked out just fine for their partner. The participants did not express any problems with this; instead, they described that their partner enjoyed the meals and had a good appetite:

He's always been that way, that he eats everything... And it isn't [a problem] now either. (Spouse A)

Participants who had always had the main responsibility for food preparation, which was mostly the females, were still in charge of these actions. This was referred to as old roles and routines within the couples:

$\mathrm{He}$, nah he doesn't touch this. He never has. It, he's not of that generation you know. Nah. The young men today are, they can do a lot. But these older ones, they've never needed to. So I make the food. (Spouse C) 
Table 2

Example of the data analysis process

\begin{tabular}{llll}
\hline Data on foodwork and meals & Code & Subtheme & Theme \\
\hline $\begin{array}{l}\text { Good thing there's the radio. Oh, } \\
\text { do you eat do you have the radio } \\
\text { on when you eat? Yes. Yes. Oh. }\end{array}$ & $\begin{array}{l}\text { Using radio to prevent silence } \\
\text { during meals }\end{array}$ & $\begin{array}{l}\text { Losing the day-to-day } \\
\text { conversation and addressing this } \\
\text { [laughter] Yes but you should }\end{array}$ & $\begin{array}{l}\text { Recognizing and } \\
\text { managing the range of } \\
\text { mealtime }\end{array}$ \\
$\begin{array}{l}\text { always try to do your best. Uh huh. } \\
\text { And I don't like having complete } \\
\text { silence around me. Nah. Instead }\end{array}$ & & \\
$\begin{array}{l}\text { I want to have a little sound. Uh } \\
\text { huh. anyway. (Spouse A) }\end{array}$ & & \\
\hline
\end{tabular}

\section{Enjoying new mealtime routines}

There were participants who had become more involved in food preparation, or had even having taken over the main responsibility over the years, but they stressed that this had happened independently of the partner's disease. Such changes in these daily routines had happened for instance, after retirement. This was mentioned as a source of enjoyment; and only described by male participants:

She'd rather go out and work. So it looks a bit strange. She goes out and I go in and make food [laughs]. But that's the way it is. (Spouse $\mathrm{H}$ )

The meals were not only seen as something that either the participants or his/her partner carried out. Instead, some spouses described it as teamwork and as an activity the couple did together. This included deciding what to have for dinner and shopping, as well as the cooking of the meal:

Like lunch now. Yeah, he just boiled the eggs. Because I made the sauce, you know... And broiled the fish. And then he gets to set the table and do that (Spouse D).

\section{Entering a new mealtime situation}

Gradually the participants stated that they had to take on greater responsibility during mealtimes and that some routines needed to be changed. Participants described that they expected things to become worse, and therefore tried to focus on the good aspects, and concentrate on what was working out well, rather than focusing on the partners inability. This was described as a way of 'charging the batteries' until more severe problems would occur. However, this was also a time where the participants stated that they had to start living a new life. Further it was described that their lives were becoming more limited, for instance, when the partner stopped showing interest in going shopping, which used to be a mutual activity. Mealtimes could also change due to the person with dementia attending a day care centre where they were having their meals. Even if this was not seen as a problem, it was something the participants felt they had to adapt to and learn to accept. Participants said that they sometimes experienced a loss where they missed having meals with their partner:

I've been alone before you know, when he's been at work and such. But it's been natural... This is, you know there's a little. What can I say, feeling of loss in this. (Spouse E)

\section{Detecting and adapting to shortcomings in preparing meals}

More severe changes and problems were also described among the participants, as well as increased responsibility for meals since their partners' ability had been affected by the disease. This included that the partner with dementia had trouble managing the shopping, setting the table and cooking the food. Partners were no longer able to take the initiative regarding what to eat, chose to stay out of the kitchen, and were referred to as someone who no longer had an interest in preparing meals. It was stressed that, as a result of the dementia, the partners were no longer able to cook since they could not handle this complex situation and, for instance, the food would turn out too spicy or some ingredients would be forgotten.

I don't know if she notices it herself. She might not but I see a bit that for her it's like 'I forgot that because I didn't do it in the right order' (Spouse H).

Spouses who had taken over the responsibility of meal preparation in order to uphold the couple's routines, mentioned that the partner's knowledge and experience were needed, as the spouse was insecure about how things should be done.

She can you now set out a candle and light it ... and she even sets out a flower sometimes which she does when she comes down to... I don't see that at all. I see it when she does it but I never think about it... she's much more careful with that than I am. (Spouse H)

One way to manage the situation was to help the partners with dementia maintain activities they had performed in the past. Training at the day care centre was also mentioned as helpful for their partners, especially assisting with preparing and during mealtimes. For instance, one participant described that the partner 
was again able to set the table as a result of training to undertake this task. For some of the participants, trying to involve the partner in food preparation was mentioned with some participants explaining that giving orders or delegating tasks allowed them to help their partner carrying out activities. Getting out ingredients helped the partner recognize and understand what they were supposed to do. Reminding the person with dementia of the process involved in food preparation was another way to make these individuals aware of what was going on and involve them. Participants also highlighted that during this time they also needed to be aware of maintaining their partners dignity and protecting them from losing face. Therefore, communication became important:

And then I sort of didn't want to show that 'Hey, we've eaten so you shouldn't have any more'. Instead I said 'I don't think it's been very long since we ate. Don't you think we should have a cup of coffee a little later instead?'. (Spouse E)

When the person with dementia used to be responsible for the preparation of meals it could become a problem as the spouse was unfamiliar and unsecure in regards to preparing food meaning that there was no longer anyone in the household who was able to manage these activities. One solution described was when a couple was unable to prepare food for themselves, they used the meals-on-wheels service. Even when able to perform such activities, receiving food from the meals-on-wheels service or using ready-cooked meals was found to be a way of decreasing spouses' workload. However, even though this was described as good resource to use and the food was of an acceptable quality, the scent of homecooked meals was said to be missed.

Another way to manage the situation was to exclude the partner from preparing meals. This was only mentioned by spouses who had taken over the main responsibility for these activities later in life, and was attributed to the fact that the partner with dementia was in the way. There was not enough room for both of them because the kitchen was too small for two people, and the partner was also no longer able to manage or assist in the cooking. One participant also described that he preferred to be alone in the kitchen because he had to do things in a certain way.

I work best, I think, when I can be alone in the kitchen so I. Because we don't really work the same way... Yeah, I guess I'm more... Planner so I, I do exactly the same thing every time. Because that way I don't forget anything...So it's exactly the same thing all the time. (Spouse H)

\section{Adapting eating habits and upholding nutritional intake}

The study found that on occasions the partners had problems with upholding good nutrition intake. This was found to be due to: a decreased appetite, but could also either be due to forgetting to eat or eating constantly. The severity of these problems could vary from one occasion to the next. Drug treatment for dementia disease were described as helpful for their partners regarding such problems, and one participant believed that the drug treatment had helped the partner eat at more slowly.

Spouses wanted to do the right thing for their partners, by helping the partner uphold a good nutritional intake. There were participants telling that they tried to get their partner to increase their energy intake, for instance by using products containing more fat. Furthermore, some participants described that they chose to prepare food their partner was fond of and avoided dishes or ingredients the partner did not like in order to increase their food intake. Another spouse described helping his partner during meals by eating her leftovers, since she was not able to eat everything herself. The participant stated that this was a way in which he could maintain his wife's dignity and protect her. This was also experienced as a responsibility the spouses had, and could resulted in them blaming themselves when the partners ate less. One participant said:

But I guess I have poor imagination and simply are a bad cook. I think I understand, it's bad variation on it [the food]. (Spouse F)

Changed eating behavior of the partner with dementia was also noticed, for example; avoiding certain foods, enjoying desserts more, or imitating what the spouse ate.

But if I took the potatoes first and put a potato on my plate and then he took the bowl and then he put a potato on his. (Spouse E)

Participants spoke of the way the partner would imitate their behavior, this could be used as a mechanism to make the individual with dementia eat more. One way in which this was achieved was by putting more food on their own plate. This was found to entice the partner take a larger portion as well.

\section{Losing the day-to-day conversation and addressing this concern}

Sometimes there was a lack of conversation during meals, which for instance resulted in participants no longer receiving appreciation for the food they had prepared. Overall, participants described that couples talked less with each other, and it was hard to sustain a conversation around the kitchen table.

He sort of doesn't care at all about what happens... he listens to what I say but he...there's sort of never any conversation... he just lets it go by. (Spouse C)

The participant described this with a sense of sadness, and as the partner lost the ability to be involved in the conversation, the spouse also stopped talking during mealtimes. It was mentioned how they learned to accept this silence with some using the radio as a way to break 
the silence.

However, in regards to conversations during mealtimes, there were certain strategies described by the participants to encourage the partner converse at the table. Discussing things that had happened in the old days, or in this very moment, sometimes made it possible to have a conversation. With the spouse giving clues, the partner was made aware of what the spouse was talking about:

Then I have to, if for example I'm going to talk about [the summer house]...then I have to first say 'You know, know [the summer house] in the kitchen' I say. Then he has to think a good long time. Because he doesn't know right away what the kitchen is and where [the summer place] is. Instead he has to sort of lead himself into it...Then he can see how it looks...if I describe it a bit. (Spouse B)

\section{Discussion}

The results identified of one major theme, that being, Recognizing and managing the range of mealtime changes, with the spouses experiences varied depending on where the families were in the progression of dementia. There were spouses who described that mealtimes worked as usual, meaning that the partner with dementia played an active role in the shopping, cooking and eating of meals. As changes occurred in the disease process, spouses described that the couples routines, responsibilities and relationship were affected, and in the interviews spouses highlighted solutions to manage changes including getting support from the social care and health care services, but also strategies they had learned and employed by themselves.

Mealtimes were sometimes referred to as being similar as before, and if there were changes, these were due to other reasons than the partner's disease. This is a significant result as dementia is associated with decreased functional capacity and difficulties in performing activities (3), but agrees with the results of von Kutzleben et al. (25) research. According to these authors, community-dwelling persons with dementia described trying to carry on doing the things they used to doing, and continuing to live their lives as before. One explanation for why mealtimes worked out well for the partners with dementia in this study might be related to the fact that these individuals were in the early stage of their disease, which was confirmed by the MMSE scores indicating mild to moderate dementia, according to Jönsson and Wimo's (22) interpretation. However, this is important from the spouses' perspective as it indicates that mealtimes might actually be something that can be beneficial to the couple and perhaps serve as a way in maintaining relations and closeness within a couple. This is confirmed in a study by Hellström, Nolan and Lundh (26), where it was found that sharing activities like food preparation can help couples where one partner has a dementia to stay engaged with one another. Furthermore, according to the recently developed Life Nourishment Theory (LNT) $(19,27,28)$, meal preparation and eating together can help couples living with dementia, stay together as a unit and maintain their relationship by including social activities and an emotional connection (28). This was also found in this study, where spouses described food preparation as teamwork and something the couple did together.

However, changes in responsibilities regarding mealtimes as a result of the partner's dementia did occur, which has previously been found in other studies $(29,30)$. Such changes occurred successively, and some participants described only small changes, whilst other described more significant changes leading to trouble with managing the shopping, setting the table and cooking the food. Therefore staff supporting people with dementia and their spouses need to continually assess and plan for the care to be provided (8). This is of importance so that spouses can be, as much as possible, prepared as changes in the individual with dementia occur. Furthermore, by continuously meeting the families one might think that it will be easier for staff to support the families based on their individual needs, as that leads to a deeper understanding regarding what families are facing in their everyday life.

In line with the LNT (19), this study showed that not only do mealtimes change when a family member has dementia, but also that families adjust, on the whole, to these changes and develop strategies to manage them. Here, participants described that they attempted to involve their partner during meal preparation and also to maintain old habits and routines during mealtimes. According to Persson and Zingmark's (29) findings, spouses wanted to preserve former activities and roles even though new responsibilities were part of life when living with a partner with dementia. How spouses adjusted to changes, as well as their experience regarding meals, probably depended on whether they used to be in charge of this specific activity, or if this was something they had taken over later in life. Handling meal preparation has traditionally been considered a female role (31), and previous studies have described that men experience it as an unfamiliar situation even though they had sometimes played a peripheral role in this task in the past $(9,10)$. Participants in the present study also described an increased responsibility that they preferred to be alone to carry out, or that their partner's knowledge and experiences were used to manage these activities. In a study by Johansson et al. (2013) nursing staff stressed that spouses are important for helping the person with dementia with food preparation, but also that these individuals need information and support to be able to care for their partner with dementia (8). This seems to be in agreement with the results found in this study, that it could be troublesome when a spouse who has never been responsible for food preparation, 
needs to take over such activities. Here, meals-on-wheels and ready-cooked meals were described as ways for the couples to manage, which is the most commonly support received from the social care (32). However, staff have highlighted that they want to provide more support during the preparation of meals at home (8), with these results useful for helping staff increase their knowledge on how to support older persons in their homes. For instance, spouses described how they delegated tasks and reminded the partner, with dementia, of the process of food preparation in a way to maintain the other persons dignity. For spouses in need of support to manage food preparation, cooking classes could be offered (8). Cooking classes for older persons have previously been described as an opportunity to learn to cook as well as meet others and create new networks (33). Meeting others and sharing meals can be of great importance not least since the results of this study revealed changes regarding social interaction during meals. It was found that some partners with dementia were no longer able to communicate as before, and participants experienced a loss regarding this which is important for staff to pay attention to. This may affect the couple's relationship, and is in line with the results of the study by Walters et al. (6) showing that a lack of conversation changed the pattern of daily life in some couples. It has also been found that the loss of conversation can make a spouse see his or her partner as a different person from before, which could lead to a disruption or breakdown of marital closeness (34). Participants described that they had learned to communicate with their partners in a way that protected the partner from losing face and instead involved them in conversations. According to the LNT, through reminiscing during meals, people with dementia can be involved in the conversation and maintain their selfworth (27). Furthermore, even though changes occur, and relationships seem to be affected negatively as a result of the disease, the sharing of meals might on the other hand help families honor individual and family identities (27). Hence, the results of this study also indicate that when one person in a couple develops dementia, both are affected, but also that couples adapt and adjust to changes that occur.

Some methodological considerations have arisen along the way with this study and need to be discussed. To begin with, this study only described spouses' experiences of mealtimes. The results are therefore onesided, and do not give a full description of the mealtime situation for the couple. Interviews with the couple could be one way to obtain further knowledge about this phenomenon. Furthermore, in this study the spouses were asked to participate because their partner had participated in another research project. The individuals with dementia were informed about that project by their primary nurses, and few people were asked to participate. It is therefore likely that the couples who participated in the former project are those experiencing the least problems, which also might have affected the present study. However, several hours were spent in the home of each couple and a trustful relationship was established, which hopefully allowed the spouses to talk openly about mealtimes in their homes, with the results covering a large variation in experiences. The first and third authors read the interviews independently, and the analysis continued until they agreed that the themes accurately described the content of the interviews. Further, the analysis was discussed at different stages with the other authors as well, which according to Lincoln and Guba (24) strengthens credibility, dependability and confirmability.

\section{Conclusion}

Paying attention to mealtimes is important; both from a nutritional point of view but also in order to gain an understanding about daily life and what kind of challenges couples (when one partner has a dementia) faces. The results revealed that depending on where the couples were in the change of dementia their experienced varied and both have learn how to adapt to such changes. Spouses described different experiences considering mealtimes which indicates that it is important that support is based on individual needs. Nursing staff should therefore continuously pay attention to a couples mealtime situation and revise care plans when necessary. It is more common that people today tend to live in their own homes for a longer period of time, and research into nursing interventions is necessary to increase the knowledge about best practice in supporting people with dementia and their spouses to allow them to live at home as long as possible. These results generate an insight into what couples face, and their needs for support. Further it increases staff's knowledge regarding possible solutions on how to involve persons with dementia in mealtime activities and maintain their nutritional intake.

Conflict of interest: None.

\section{References}

1. Agüero-Torres H, Thomas V.S, Winblad B, Fratiglioni L.The impact of somatic and cognitive disorders on the functional status of the elderly. Journal of Clinical Epidemiology 2002;55: 1007-1012.

2. World Health Organization and Alzheimer's Disease International, 2012, Dementia- a public health priority. WHO Press. http:/ / whqlibdoc.who.int/ publications/2012/9789241564458_eng.pdf. Accessed 21 December 2013.

3. Aselage MB, Amella EJ. An evolutionary analysis of mealtime difficulties in older adults with dementia. Journal of Clinical Nursing 2010;19: 33-41.

4. Watson R, Green SM (2006) Feeding and dementia: a systematic literature review. Journal of Advanced Nursing 2006;54: 86-93.

5. Johansson L, Sidenvall B, Malmberg B, Christensson L. Who will become malnourished? A prospective study of factors associated with malnutrition in older persons living at home. Journal of Nutrition, Health \& Aging 2009;13:855-861.

6. Walters AH, Oyebode JR, Riley GA. The dynamics of continuity and discontinuity for women caring for a spouse with dementia. Dementia 2010;9: 169-189.

7. Keller HH, Edward GH, Cook C. Mealtime Experiences of Families With Dementia. American Journal of Alzheimer's Disease \& Other Dementias 2007;21: 431-438. 
8. Johansson L. Foodwork and meals in everyday life among persons with dementia and their partners. Dissertation, School of Health Sciences Jönköping University, 2013.

9. Fjellström C, Starkenberg Å, Wesslén A, Tysén Bäckström AC, Faxén-Irving G. To Be a Good Food Provider: An Exploratory Study Among Spouses of Persons With Alzheimer's Disease. American Journal of Alzheimer's Disease and Other Dementias 2010;25: 521-526.

10. Atta-Konadu E, Keller HH, Daly K. The food-related role shift experiences of spousal male care partners and their wives with dementia. Journal of Aging Studies 2011;25: 305-315.

11. Russell R. In sickness and in health: A qualitative study of elderly men who care for wives with dementia. Journal of Aging Studies 2001;15: 351-367.

12. Calasanti T, King N. Taking 'Women's Work' 'Like a Man': Husbands' Experiences of Care Work. The Gerontologist 2007;47: 516-527.

13. Sanders S, Power J. Roles, responsibilities, and relationships among older husbands caring for wives with progressive dementia and other chronic conditions. Health and Social Work 2009;34: 41-51.

14. SOU 2003:91. Äldrepolitik för framtiden. 100 steg till trygghet och utveckling med en åldrande befolkning. Elderly policy for the future. [Swedish]. http:/ / www.regeringen.se/sb/d/108/a/2611. Accessed 12 September; 2003;

15. Tanner B, Tilse C, de Jonge D. Restoring and sustaining home: The impact of home modifications of the meaning of home for older people. Journal of Housing for the Elderly 2008;22: 195-215.

16. de Jonge DM, Jones A, Philips R, Chung M. Understanding the essence of home: Older people's experience of home in Australia. Occupational Theraphy International 2011;18: 39-47.

17. Socialstyrelsen, 2005; Boende och vårdinsatser för personer med demenssjukdom. Housing and health care for persons with dementia [Swedish] http:/ / www.socialstyrelsen.se/Lists / Artikelkatalog/Attachments /10107/2005-123-5_20051235.pdf. Accessed 12 February 2014.

18. O'Malley L, Croucher K. Housing and dementia care-a scoping review of the literature. Health \& Social Care in the Community 2005;13: 570-577.

19. Genoe MR, Keller HH, Martin LS, Dupuis SL, Reimer H, Cassolato C, Edward G. Adjusting to Mealtime Change within the Context of Dementia. Canadian Journal on Aging/La Revue canadienne du vieillissement 2012;1: $1-22$

20. Amella EJ, Aselage MB. Mealtime difficulties. In $\mathrm{O}^{\prime}$ Meara A, Fulmer TT, Zwicker D, Boltz M (Eds.), Evidence-Based Geriatric Nursing Protocols for Best Practice (2011;4 ed., p. 453-468). New York: Springer Pub.
21. Braun V, Clarke V. Using thematic analysis in psychology. Qualitative Research in Psychology 2006;3, 77-101.

22. Jönsson L, Wimo A. The cost of dementia in Europe: a review of the evidence and methodological considerations. Pharmacoeconomics 2009;27: 391-403.

23. Polit DF, Beck CT. Nursing research.: generating and assessing evidence for nursing practice (9 ed.) Philadephia: Wolters Kluwer Health/Lippincott Williams \& Wilkins, 2012.

24. Lincoln YS, Guba EG. Naturalistic in quiry. Newbury Park, California: Sage Publication, 1985.

25. von Kutzleben M, Schmid W, Halek M, Holle B, Bartholomeyczik S. Community-dwelling persons with dementia: What do they need? What do they demand? What do they do? A systematic review on the subjective experiences of persons with dementia. Aging \& Mental Health, 2012. doi: $10.1080 / 13607863.2011 .614594$.

26. Hellström I, Nolan M, Lundh U. 'We do things together': A case study of 'couplehood' in dementia. Dementia 2005;4: 7-22

27. Genoe R, Dupuis SL, Keller HH, Martin LS, Cassolato C, Edward HG. Honouring identity through mealtimes in families living with dementia. Journal of Aging Studies 2010;24: 181-193.

28. Keller HH, Schindel Martin L, Dupuis S, Genoe R, Edward HG, Cassolato C. Mealtimes and being connected in the community-based dementia context. Dementia 2010;9: 191-213.

29. Persson M, Zingmark K. Living with a person with Alzheimer's disease: Experiences related to everyday occupations. Scandinavian Journal of Occupational Therapy 2006;13: 221-228.

30. Quinn C, Clare L, Pearce A, van Dijkhuizen M. The experience of providing care in the early stages of dementia: An interpretative phenomenological analysis. Aging \& Mental Health 2008;12: 769-778.

31. DeVault M. Feeding the family. Chicago: University of Chicago Press, 1991

32. Berensson K. Öppna jämförelser 2009. Folkhälsa. Comparisons on public health [Swedish]. 2009, Sveriges kommuner och landsting, Stockholm, 2009.

33. Nydahl M. Matskola för äldre. Implementering av resultat från EU-projektet Mat på äldre dar - att välja mat och inta måltider: att bevara oberoende och livskvalitet. Cookery classes for older persons. [Swedish] http:// www.vardalinstitutet.net/sites / default/files/tr/naring/naringdocs / naringartikelpdf/6692.pdf. Accessed 12 March 2014 [Swedish], 2007.

34. Boylstein C, Hayes J. Reconstructing Marital Closeness While Caring for a Spouse With Alzheimer's. Journal of Family Issues 2012;33: 584-612. 